\title{
Artigo \\ Protótipo de um dinamômetro de baixo custo para medição de força muscular
}

\author{
Marciel Bezerra de Moura ${ }^{[1]}$, Idalmir de Souza Queiroz Junior ${ }^{[2]}$ e Mateus Ânderson B. Duarte ${ }^{[3]}$ \\ [1] Universidade Federal Rural do Semi-Árido (UFERSA); gmarcielllbezerra@ gmail.com \\ [2] Universidade Federal Rural do Semi-Árido (UFERSA); idalmir@ ufersa.edu.br \\ ${ }^{[3]}$ Universidade Federal Rural do Semi-Árido (UFERSA); mateusanderson@hotmail.com.
}

Recebido: $10 / 06 / 2020$;

Aceito: 09/08/2020;

Publicado: 11/09/2020.

Resumo: Na área medicinal, a utilização de instrumentos de medição precisos para a determinação de diagnósticos melhores e mais rápidos tem sido um dos grandes avanços da tecnologia. Porém, esses avanços geralmente, quando acontecem, possuem um custo bastante elevado. Assim, este trabalho trata da criação de um protótipo para a medição de força muscular, destinado à implementação na área fisioterapêutica, utilizando recursos de baixo custo e material de fácil acesso, a partir de células de carga com capacidade máxima de 100 quilogramas, sendo possível, assim, sua utilização em diversos membros do corpo. Este trabalho apresenta a construção do protótipo desde a sua concepção, dimensionamento dos sensores utilizados, até a sua montagem final. O protótipo desenvolvido foi testado experimentalmente e levantados os resultados de sua calibração utilizando pesos com valores conhecidos. O protótipo possui um sistema embarcado que registra todas as medições feitas, além de possuir uma interface com o usuário de fácil utilização. O dispositivo foi desenvolvido a partir da plataforma Arduino, simulado e construído seguindo os passos dimensionados em seu projeto. Após a construção do protótipo, várias medidas foram efetuadas para a comprovação da viabilidade da sua utilização na área medicinal, mostrando assim seu possível uso como instrumento médico.

Palavras-chave: Célula de carga. Medidor de força muscular. Protótipo de baixo custo. Eletrônica embarcada. Arduino.

Abstract: In the medical field, the use of accurate measuring instruments to determine better and faster diagnoses has been one of the great advances in technology. However, these advances generally, when they happen, have a very high cost. Thus, this work deals with the creation of a prototype for the measurement of muscular strength, intended for implementation in the physiotherapeutic area, using low-cost resources and easily accessible material, from load cells with a maximum capacity of 100 kilograms, being possible thus, its use in several members of the body. This work presents the construction of the prototype from its conception, dimensioning of the sensors used, until its final assembly. The developed prototype was tested experimentally, and the results of its calibration were surveyed using weights with known values. The prototype has an embedded system that records all measurements made, in addition to having an easy-to-use user interface. The device was developed from the Arduino platform, simulated and built following the steps dimensioned in your project. After the construction of the prototype, several measures were taken to prove the feasibility of its use in the medical field, thus showing its possible use as a medical instrument.

Keywords: Load cell. Muscle strength meter. Low-cost prototype. Embedded electronics. Arduino.

\section{INTRODUÇÃO}

A tecnologia ao longo dos anos vem se desenvolvendo e se apresentando como uma forma de melhorar a vida da população, seja por descobertas de novas técnicas ou pela melhoria de conhecimentos que já são 
utilizados. Muitas dessas tecnologias são muito caras dificultando o acesso pela população mais carente. $\mathrm{O}$ projeto de ferramentas e instrumentos alternativos de baixo custo para a área possui uma demanda enorme.

A criação de um protótipo para a medição de força muscular utilizando um microcontrolador é um projeto dedicado a suprir essa demanda na área da saúde, mais especificamente na área do estudo muscular ou da área de fisioterapia, contribuindo assim para a melhoria do serviço medicinal do Brasil. O projeto utiliza um Arduino na prototipagem e componentes de baixo custo, como os sensores e ferramentas simples. A utilização de um instrumento capaz de medir força é bastante comum na área da saúde, esses instrumentos mostram como está o estado dos músculos de determinados pacientes. Na fisioterapia, por exemplo, um fisioterapeuta pode avaliar o progresso muscular de um paciente com lesão a partir da força que ele exerce sobre um instrumento com essa finalidade.

Faz-se então necessário a utilização de tecnologias que melhorem a coleta dos dados necessários para um diagnóstico mais preciso, melhorando então a qualidade do serviço ao paciente, assim como a qualidade de vida das pessoas que dependem desse tipo de diagnóstico. O projeto, então, visa responder a seguinte pergunta: é possível criar um instrumento relativamente preciso e de boa qualidade, utilizando ferramentas e materiais de baixo custo, que possa ser utilizado como complemento para instrumentos de diagnóstico de força mais caros?

Alguns instrumentos de medição são utilizados como alternativas para medir a força de músculos em determinadas posições, porém, geralmente são instrumentos analógicos, mais robustos e mais imprecisos. Um instrumento analógico preciso acaba sendo muito mais caro do que um digital. Logo, um instrumento de medição de força muscular digital e preciso, é um instrumento muito caro, devido ao mesmo não ser encontrado facilmente no Brasil, e por ser necessário na área da saúde. Logo, o projeto proposto tenta viabilizar a construção deste instrumento utilizando material de baixo custo e disponibilizá-lo a universidade ou às instituições privadas locais para a sua utilização e melhoria do projeto. Assim, o projeto consiste na utilização de uma plataforma acessível e barata, o Arduino, para a criação de um instrumento capaz de realizar medições e registros de força muscular, com a finalidade de obter dados referentes à qualidade dos músculos de um determinado paciente examinado com o instrumento, utilizando então esses dados para a obtenção de diagnósticos melhores e mais precisos.

\section{REFERENCIAL TEÓRICO}

A balança é uma tecnologia utilizada pelo homem a muito tempo, a cerca de 5000 A.C. e desde os primórdios, foi utilizada como uma forma de medir um peso de determinado material [1]. Esse tipo de tecnologia é bastante variado, existem balanças analógicas, que funcionam a base de molas, hastes rígidas, entre outros, balanças por comparação de pesos, ou balanças digitais com diversos tipos de células de carga. As células de carga não têm simplesmente a finalidade de medir pesos, como é o caso da balança, algumas tem outras aplicações que utilizam o princípio da medição de pesos para a medição de uma grandeza diferente, como por exemplo, a medição de uma força, que está relacionada com a força peso.

A balança é muito utilizada para fins comerciais, onde a grandeza exibida a um usuário é sua massa, geralmente dada em quilogramas, e é obtida quando um determinado material é posto sobre esta balança. Neste caso, a massa indica uma proporcionalidade física com a força depositada na balança, onde essa força é chamada de força peso. Força é uma interação entre dois corpos ou entre o corpo e seu ambiente [2], é um resultado da multiplicação entre duas grandezas, a massa e a aceleração. No caso da aceleração adotada para a medição de forças estáticas em uma balança, considera-se a aceleração da gravidade, que representa aproximadamente 9,81 $\mathrm{m} / \mathrm{s}^{2}$, sendo um valor aceito para todo o planeta, podendo variar entre regiões e pressões diferentes, assim, é possível obter o valor da massa aproximada de qualquer objeto a partir de uma força peso medida em uma balança.

No caso de um medidor de força, a força obtida geralmente é medida em newtons, onde não há conversão direta como no caso da balança. Na medicina, porém, por se tratar de uma unidade física acaba fugindo um pouco do senso popular, tornando assim a unidade um pouco difícil de ser interpretada. Devido a necessidade de aproximação com o usuário, alguns instrumentos possuem a unidade quilograma como unidade de exibição de uma força peso localizada. Logo a força pode ser medida utilizando o mesmo princípio da balança, podendo assim ser determinada a força muscular de um determinado indivíduo. Força muscular é a capacidade fisiológica da musculatura produzir ou gerar determinada tensão ou compressão [3]. Logo, os músculos devem se contrair, de forma a realizar um movimento ou simplesmente para manter os ossos alinhados visando o equilíbrio postural. $\mathrm{O}$ corpo humano possui três tipos de contrações musculares capazes de gerar algum tipo de tensão: a contração isotônica - realizada dinamicamente contra resistência à medida que o músculo se alonga (excêntrica) 
ou se encurta (concêntrica) na amplitude de movimento existente; a contração isocinética - forma de contração isotônica, na qual a velocidade e o encurtamento do músculo são controlados por um equipamento limitador; e a contração isométrica - realizada estaticamente quando um músculo se contrai sem mudança apreciável no seu comprimento [4].

A manutenção dessa força muscular é de extrema importância, pois os movimentos do corpo humano precisam da força muscular para ocorrer, seja para atividades físicas desportivas, atividades laborais, recreação etc. Logo, o comportamento dessa força em pacientes que sofreram algum tipo de impacto muscular, seja por acidentes, por doenças ou por algum tipo de anomalia, deve ser medido e acompanhado de forma precisa para detalhar ao máximo o diagnóstico e assim determinar o tipo de tratamento em que o indivíduo irá necessitar. Faz-se então necessário a utilização de ferramentas médicas para a obtenção de dados referentes a essa força muscular atuando no paciente.

\subsection{Medidores de força fisioterapêuticos}

$\mathrm{Na}$ área medicinal, a força que é determinada por parte do corpo, pode ser de suma importância, pois pode ser quantificada para cada biotipo, sendo possível adotar um padrão. Assim, pode-se chegar a diversos diagnósticos musculares ou até mesmo ortopédicos a partir de resultados da força exercida por um determinado membro, por exemplo. Existem diversos tipos de medidores de força empregados na área fisioterapêutica, como exemplo se tem o dinamômetro digital de mão, ou o dinamômetro Jamar demonstrado nas Figuras 1 e 2 respectivamente, que são instrumentos utilizados para medir a força máxima que a mão consegue exercer de acordo com a tensão ou a contração que ela exerce sobre um transdutor ou sensor interno do instrumento [5].

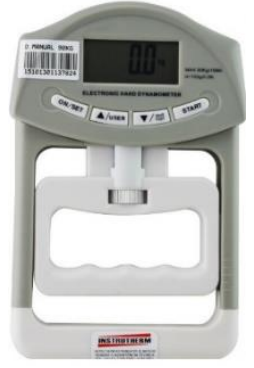

FIGURA 1. Dinamômetro digital de mão [6].

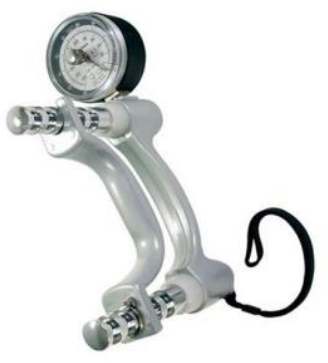

FIGURA 2. Dinamômetro Jamar [7].

Porém, esses instrumentos não possuem um sistema de medição aprimorado para a execução de um diagnóstico mais preciso, além disso, funcionam restritamente como medidores de força muscular na região das mãos, não sendo possível a sua utilização para a determinação de diagnósticos em outros membros do corpo. Alguns instrumentos da área fisioterapêutica conseguem ser mais eficientes, abrangendo uma boa captação dos dados e uma maior precisão do diagnóstico, porém devido a essa eficiência, ainda são muito caros e pouco utilizados. Assim, surge a necessidade da utilização de instrumentos alternativos que possuam uma boa precisão e que não sejam tão caros.

\subsection{Arduino}

Utilizando componentes de baixo custo, é possível a criação de um instrumento preciso e eficiente para ser utilizado não só em uma parte do corpo ou apenas em um tipo de teste, mas sim utilizado em vários membros e de várias maneiras. Para isso, o Arduino é utilizado como uma plataforma para processar os dados obtidos de um determinado sensor ou transdutor de força, sendo possível assim a obtenção de parâmetros como, por exemplo, a força máxima executada em determinado intervalo de tempo.

O Arduino, é uma plataforma de código aberto e de fácil acesso que foi criado com o intuito de aumentar o acesso a iniciativa tecnológica, devido ao mesmo ser barato e possuir uma linguagem de programação mais acessível. Esta é a maior vantagem do Arduino sobre outras plataformas de desenvolvimento de microcontroladores, a facilidade de sua utilização. Pois assim, é possível que pessoas que não são da área consigam rapidamente replicar ideias e criar seus próprios projetos em um intervalo de tempo relativamente curto [8].

O Arduino possui uma característica bastante importante, vários sensores podem ser colocados facilmente em sua placa, assim como sistemas inteiros que aumentam as suas características iniciais e as suas funções, 
comumente chamados de Shields ou módulos. O Arduino, por ser uma plataforma mais fácil e por possuir componentes mais baratos, tem grande importância na prototipagem. A utilização do Arduino está atrelada a sua função de ser um controlador que consegue integrar vários sensores e/ou Shields para a utilização em um protótipo, utilizando um microcontrolador que possui uma lógica definida pelo usuário. O Arduíno possui vários modelos, como o Arduino Nano, o Arduino UNO, Arduino Leonardo, Arduino MEGA etc. Cada um utilizado para aplicações diferentes. O Arduino UNO é geralmente o mais utilizado, por ser a plataforma mais famosa da família Arduino.

O componente principal da placa Arduino UNO é o microcontrolador ATMEL ATMEGA328, que trata do cérebro da plataforma, onde todo o código é gravado e processado. O ATMEGA é um dispositivo de 8 bits de processamento e conta com $32 \mathrm{~KB}$ de memória Flash, onde 512 Bytes são utilizados para o bootloader, software interno que controla o Arduino. Possui 2 KB de memória RAM e 1 KB de memória EEPROM. Pode operar a até $20 \mathrm{MHz}$, porém na placa Arduino UNO opera em $16 \mathrm{MHz}$ [10].

A plataforma possui 6 pinos que podem ser utilizados como entradas ou saídas analógicas, onde é possível a utilização de componentes que utilizem tensões que variem entre 0 a 5 volts, e 14 pinos que podem ser utilizadas como entrada e saídas digitais, ou seja, pinos que operam em 0 e 5 volts, funcionando como chaves liga/desliga.

A programação do Arduino é feita através da comunicação serial com um computador, através de um cabo de alimentação USB do tipo B. O código lógico (Algoritmo) do Arduino é escrito no programa Arduino IDE (Integrated Development Environment), ambiente de desenvolvimento da lógica do Arduino, disponibilizado gratuitamente no site do fabricante. Ao estabelecer a conexão com o Arduino, o programa, após ser compilado, pode ser carregado e então a plataforma começa a executar a lógica programada. A linguagem utilizada para a programação do Arduino é semelhante ao C++.

Assim, o Arduino pode ser facilmente programado para executar os mais diversos algoritmos, sendo possível a sua utilização em diversos projetos e protótipos. Não é necessária a utilização de uma linguagem de programação de baixo nível, possui várias portas podendo ser utilizado com vários sensores e transdutores. $\mathrm{O}$ Arduino UNO foi escolhido para ser utilizado no protótipo por todas essas vantagens. As especificações técnicas como tensão de alimentação e operação, estão contidas na Tabela 1.

TABELA 1. Especificações técnicas do Arduino UNO.

\begin{tabular}{cc}
\hline \multicolumn{2}{c}{ Especificações Técnicas } \\
\hline Microcontrolador & ATmega328 \\
Tensão de operação & $5 \mathrm{~V}$ \\
Tensão de alimentação & $7-12 \mathrm{~V}$ \\
(recomendada) & \\
Tensão de alimentação & $6-20 \mathrm{~V}$ \\
(limite) & 14 \\
Pinos digitais & 6 \\
Pinos analógicos & $32 \mathrm{~KB}$ \\
Memória flash & $2 \mathrm{~KB}$ (ATmega328) \\
SRAM & $1 \mathrm{~KB}$ (ATmega328) \\
EEPROM & $16 \mathrm{Mhz}$ \\
Frequência de Clock &
\end{tabular}

Fonte: Adaptado de [9].

\subsection{Célula de carga}

Para a medição de uma força ou peso, sensores devem ser empregados, seja ele mecânico, como o dinamômetro analógico, por exemplo, que possui uma mola com uma constante elástica bem definida (k). A força é regida pela Equação 1, onde o deslocamento é proporcional à força aplicada, sendo então demarcada uma escala referente a essa proporcionalidade, geralmente em quilogramas [1]. 


$$
\mathrm{F}=-\mathrm{kx}
$$

Para a utilização de um componente eletrônico para a medição de uma força, a célula de carga é o mais utilizado. É um transdutor de força, ou seja, é um dispositivo eletromecânico que tem como propriedade a medição das deformações ou a flexão de um corpo transformando-a em uma pequena diferença de potencial. Para a obtenção destes sinais é utilizado o strain gage, que converte a deformação em tensão a partir da propriedade do material empregado na fabricação, onde sua resistência elétrica varia de acordo com a deformação que o mesmo sofre, assim, em conjunto com um circuito da ponte de Wheatstone, o strain gage proporciona um sinal em mili ou microvolts que é alterada proporcionalmente à medida que se aplica maior peso ou força na estrutura, ou seja, à medida em que a deformação no strain gage aumenta [11].

O tipo mais comum de strain gage é um filme isolante flexível, onde é fixada uma estrutura metálica de forma laminar. Esse dispositivo tem seu funcionamento baseado na lei de Ohm da Equação 2, onde a resistência elétrica varia de acordo com que há uma variação no comprimento ou na área do componente. No caso do strain gage, a variação ocorre quando há uma deformação ou uma tração, existindo uma variação no comprimento (L) e na área (A), isso provoca aumento ou diminuição da resistência elétrica. Como a resistividade ( $\rho)$ é específica para cada material, não há variação, para qualquer tração ou compressão dentro da capacidade máxima do strain gage [12].

$$
\mathrm{R}=\rho \frac{\mathrm{l}}{\mathrm{A}}
$$

A ponte de Wheatstone então detecta essa variação quando conectado ao strain gage, variando a tensão de saída proporcionalmente à deformação. Logo, a tensão medida será diferente para cada valor de força ou peso posto sob o strain gage. Assim, a célula de carga é um dispositivo que pode ser utilizada para a obtenção da força que um determinado membro do corpo exerce sobre uma superfície, de modo que a força seja aplicada somente na célula. Desse modo a célula de carga irá apresentar uma pequena deformação resultando em uma diferença de potencial proporcional a sua deformação, na medida em que o usuário aumente ou diminua a força aplicada.

\section{MATERIAIS E MÉTODOS}

Utilizando a hipótese que não há no mercado um instrumento barato capaz de realizar medições precisas, além de indicar e registrar essas medições, fez-se necessário a criação de um protótipo medidor de força que seja viável economicamente. Para isso, é necessária a utilização de componentes que possuam essa característica, que sejam baratos e que atendam às necessidades da área medicinal, ou seja, devem possuir uma precisão aceitável para o trabalho. Então, para a elaboração desse protótipo, os componentes foram selecionados antes da montagem, assim foi possível a simulação, para a obtenção da melhor forma de construção e foi possível obter o preço necessário para a fabricação.

\subsection{Componentes do protótipo}

Utilizando como base o Arduino, os sensores foram dimensionados para que fosse possível a implementação do protótipo da melhor forma, utilizando componentes de fácil acesso e que sejam pequenos o suficiente para a utilização de forma embarcada, ou seja, de forma compacta o suficiente para a utilização portátil em diversos locais, em consultas, didaticamente, etc.

\subsubsection{Células de carga}

Para a prototipagem, as células que mais se adequaram tendem a ser células com uma capacidade maior, pois alguns membros do corpo, como por exemplo as pernas, exercem uma força muito alta, ultrapassando os 200 Newtons (N) para alguns casos. Assim, a célula de carga mais adequada para o trabalho é a célula de 50 quilogramas, que irá trabalhar em conjunto com outra de mesma capacidade, totalizando assim 100 quilogramas de capacidade no instrumento, ou seja, uma capacidade de aproximadamente $0,98 \mathrm{kN}$ de força máxima.

\subsubsection{Módulo amplificador hx711}


Para a utilização das células de carga em um Arduino, é necessário um módulo amplificador do sinal das células, pois as células de carga geram uma diferença de potencial muito baixa para o Arduino. Esse sinal deve ser amplificado para que haja um bom funcionamento no controlador, para isso, o módulo HX711 de 24 bits é o mais utilizado. O módulo possui terminais de entrada que podem conectar mais de uma célula, sendo possível então a utilização de duas células em conjunto, além de ser barato e de fácil acesso.

O módulo foi projetado para trabalhar diretamente com sensores em ponte de Wheatstone para aplicações de medição de forças diversas, seja por pesos colocados estaticamente ou por forças constantes sob a célula de carga. O multiplexador de entrada seleciona entre dois canais diferenciais A e B. Cada canal diferencial pode ser ligado em até duas células de carga (A+ e A- e B+ e B-) [13].

\subsubsection{Módulo SD}

Para o armazenamento dos dados, é necessário algum tipo de memória, seja ela um servidor na internet ou uma memória física. Por se tratar de um protótipo barato, a melhor escolha é o módulo SD, pois não é necessário conexão com a internet e não depende de qualquer outro fator externo. Um módulo SD é um componente eletrônico que possui um soquete para a inserção de um cartão de memória do tipo SD de qualquer tamanho, assim, utilizando um cartão SD de 8GB, o instrumento irá possuir uma memória enorme de registro e poderá ser trocado facilmente caso haja algum defeito.

\subsubsection{LCD $16 \times 2$}

Como se trata de um protótipo onde ele será utilizado para diagnósticos rápidos, faz-se necessário uma forma de exibir os valores correspondentes das medições ao usuário. O melhor display que atende aos requisitos é um display de cristal líquido 16x2, que exibe duas linhas de informação por vez na tela e se trata de um componente barato. Ao ser utilizado com uma resistência variável em seu terminal, é possível regular o contraste da tela, melhorando a utilização do protótipo.

\subsubsection{Módulo RTC}

Para a obtenção de valores temporais como os valores de data e hora, foi utilizado um módulo RTC (Real time Clock - relógio de tempo real), contendo uma bateria do tipo botão de 3V. Esse módulo registra a hora e a data como um relógio comum, funcionando mesmo com o sistema desligado devido a sua alimentação externa da bateria de $3 \mathrm{~V}$, impedindo que haja atraso ou adiantamento da hora, assim é possível o registro temporal preciso das medições no cartão e na tela.

\subsubsection{Alimentação}

Por ser um instrumento portátil, é necessário um tipo de alimentação por bateriais. É utilizado uma bateria 9V ligada diretamente ao Arduino controlada por um botão com retenção. Utilizando esse tipo de botão em série com o terminal positivo da bateria, é possível ligar e desligar o protótipo facilmente.

\subsubsection{Botões de interface}

Como o LCD utilizado exibe apenas duas linhas de informações, e o instrumento em sua utilização precisa ser zerado de tempo em tempo, fez-se necessário a utilização de botões para a fácil utilização do usuário. Dois botões do tipo pushbutton foram escolhidos para a utilização no protótipo, são botões baratos e de fácil utilização. Um botão será utilizado para a zeragem do medidor de força e outro será responsável pela integração do display com o usuário, exibindo três telas com informações variadas. 


\subsection{Simulação}

Após escolhidos os componentes, a simulação foi efetuada. A simulação é utilizada para determinar se o instrumento irá funcionar de forma satisfatória, além de mostrar como o instrumento irá se comportar na prática, ou detectar possíveis falhas no projeto. Utilizando um software de simulação de componentes eletrônicos, foi possível determinar a forma com que o instrumento irá trabalhar e como sua montagem será realizada. O circuito do protótipo está representado na Figura 3.

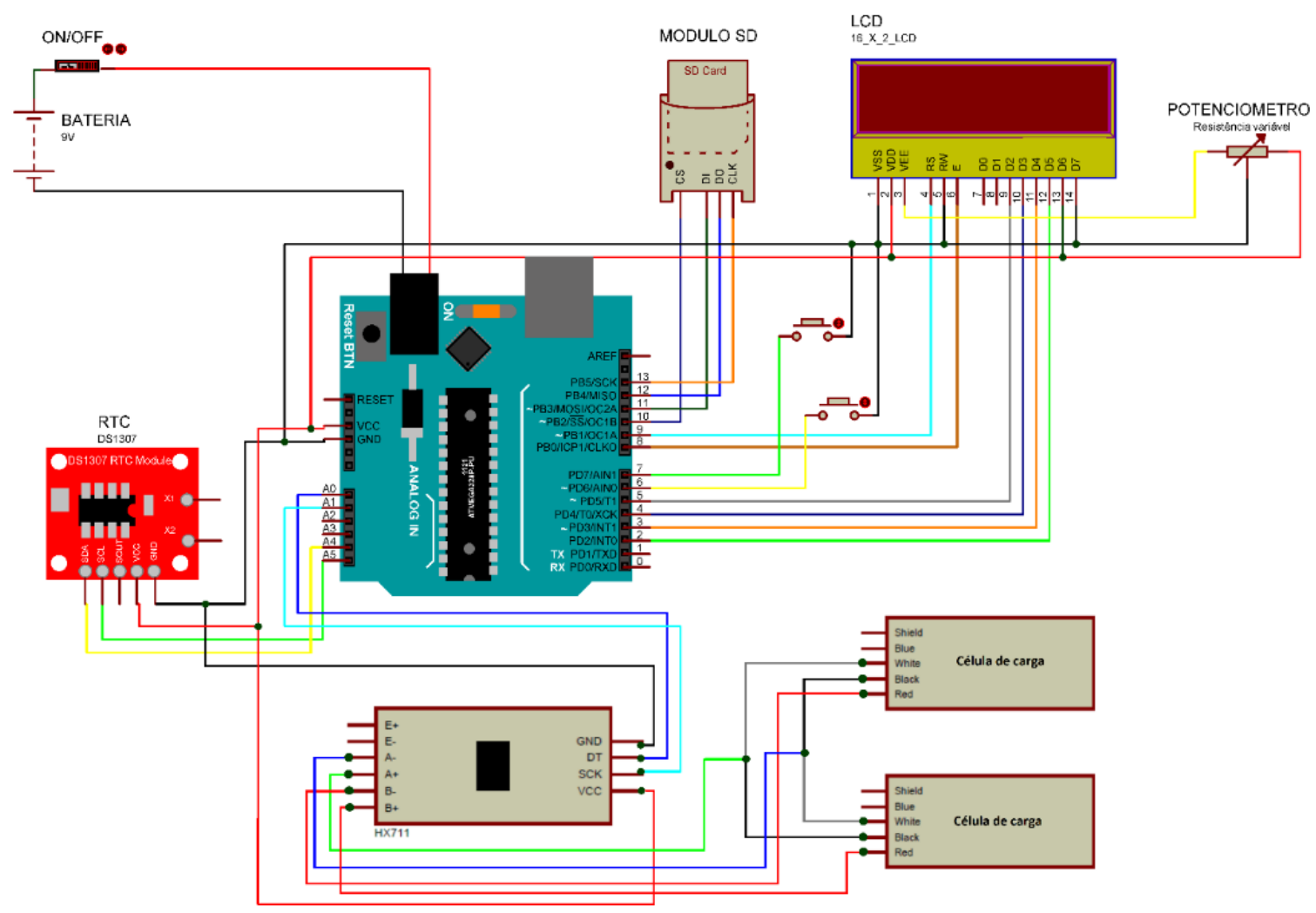

FIGURA 3. Circuito do protótipo (Autoria própria).

O circuito deverá funcionar com a seguinte lógica, as células de carga receberão uma força de até $0,98 \mathrm{kN}$, que partirá de uma força efetuada por algum membro do corpo do usuário, onde a deformação fará com que nos terminais surja uma pequena diferença de potencial. O módulo amplificador HX711 irá amplificar o sinal para que seja possível a leitura para o Arduino. Ao mesmo tempo, o Arduino receberá os sinais do HX711 e do módulo RTC, que irá enviar os dados de data e hora atuais, sendo então capaz de implementar os dados para o LCD. O LCD será responsável pela exibição das informações coletadas ao usuário. O Módulo SD será responsável pelo armazenamento dos dados no cartão SD para a futura utilização.

\subsection{Construção do protótipo}

Após a simulação do protótipo e os ajustes finais, os componentes para a fabricação do instrumento foram comprados, utilizando diversos fornecedores na internet. Os preços foram variados, porém todos os componentes tiverem um preço baixo, não chegando a 10 reais por componente, com exceção do Arduino, atendendo ao requisito de ser um protótipo de baixo custo. Os preços estão mostrados na Tabela 2. 
TABELA 1. Lista de preço dos componentes eletrônicos do protótipo (Autoria própria).

\begin{tabular}{cccc}
\hline Componente & Preço por unidade & Número de itens & Fornecedor \\
\hline Arduino UNO R3 & $\mathrm{R} \$ 13,13$ & 1 & Aliexpress.com \\
Bateria 9V & $\mathrm{R} \$ 9,99$ & 1 & Mercadolivre.com \\
Célula de carga 50kg & $\mathrm{R} \$ 2,59$ & 2 & Aliexpress.com \\
HX711 & $\mathrm{R} \$ 2,25$ & 1 & Aliexpress.com \\
LCD 16x2 & $\mathrm{R} \$ 4,92$ & 1 & Mercadolivre.com \\
Módulo SD & $\mathrm{R} \$ 9,90$ & 1 & Mercadolivre.com \\
Pushbutton & $\mathrm{R} \$ 0,20$ & 2 & Mercadolivre.com \\
RTC & $\mathrm{R} \$ 2,26$ & 1 & Mercadolivre.com \\
\hline
\end{tabular}

Nota: Valores atualizados dia 23 jun. 2019. O valor do frete não está incluso, pois varia de acordo com a região.

Com aproximadamente cinquenta reais foi possível a construção do protótipo para a medição de força muscular. Enquanto um dispositivo semelhante, como por exemplo o LAFAYETTE HAND-HELD DYNAMOMETER, custa em média mil e duzentos dólares, onde convertendo na moeda brasileira utilizando o dólar a quatro reais custa cerca de quatro mil e oitocentos reais [14]. Após a compra de todos os componentes, iniciou-se a fase de construção. Utilizando uma caixa de madeira de 16x8cm encontrado em um depósito de material reciclável, como a carcaça do instrumento, iniciou-se os primeiros dimensionamentos de como será composto o instrumento.

Como o protótipo possui duas células em conjunto, fez-se necessário uma peça de suporte que seja possível a sua utilização combinada com as células e que possua uma área para a aplicação da força, assim, a peça para o suporte foi desenhada e dimensionada de acordo com a Figuras 4. A peça consiste em uma barra soldada a um parafuso que permite o acoplamento de um disco com uma porca soldada, este disco por sua vez, será o apoio onde a força será aplicada. Os valores das dimensões da peça, representados na Figura 4 estão em milímetros.

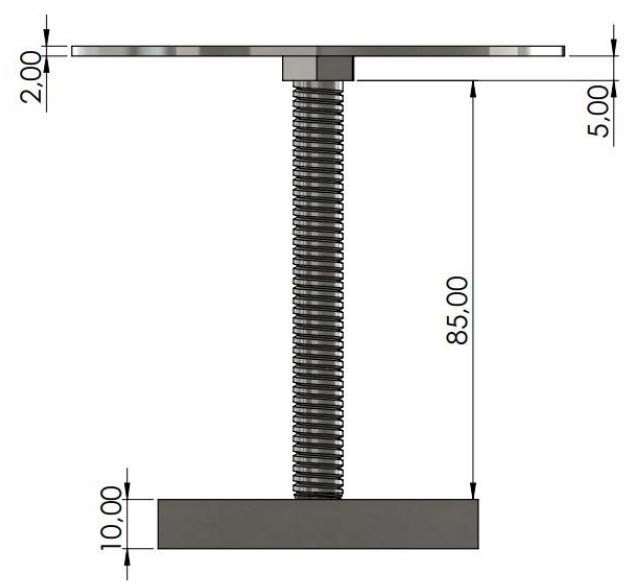

TABELA 4. Esboço 2D da peça de suporte do protótipo (Autoria própria).

Após o processo de fabricação da peça de suporte, o instrumento é montado na caixa de madeira $16 \mathrm{~cm} \mathrm{x}$ $8 \mathrm{~cm}$, iniciado pela determinação dos locais de cada componente. As células de carga possuem uma base que deverá ser elevada para que seja possível a sua deformação e para que não haja nenhuma interferência quando 
a força for medida. Para isso, utiliza-se o raiamento de bicicleta, que foi cortado e colado com cola quente nas extremidades da célula.

Após montado a base, os furos necessários para os botões e alguns componentes foram feitos e o circuito eletrônico foi montado e colocado dentro da caixa de madeira, confinado com uma pequena placa de acrílico na superfície junto com uma dobradiça, que tem o papel de facilitar a mudança de algum componente para o experimento ou algum ajuste final. O protótipo então foi finalizado com a fixação do display na caixa.

\section{RESULTADOS E DISCUSSÕES}

A partir dos componentes apresentados, foi possível então a utilização do Arduíno para cria um protótipo que atingisse o objetivo inicial do artigo. Para que o protótipo fosse capaz de testar a força de diversos membros, o mesmo deve possuir uma portabilidade, para que então o técnico a efetuar o teste possa utiliza-lo nas mais diversas posições, alguns exemplos de como o teste de força é feito, é mostrado na Figura 5.

O protótipo finalizado é mostrado então na Figura 6. A base de apoio do protótipo possui uma haste rosqueada, assim é possível a troca do disco de apoio, logo, pode haver a troca do disco facilmente, para um disco que apoie mais a uma determinada parte do corpo, facilitando o uso do instrumento.
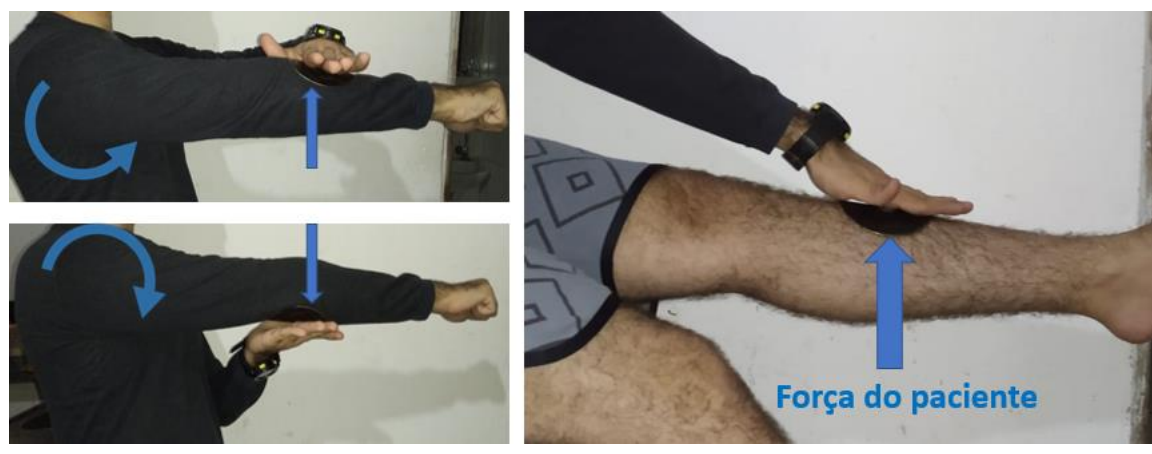

FIGURA 5. Exemplos de utilização do instrumento (Autoria própria).

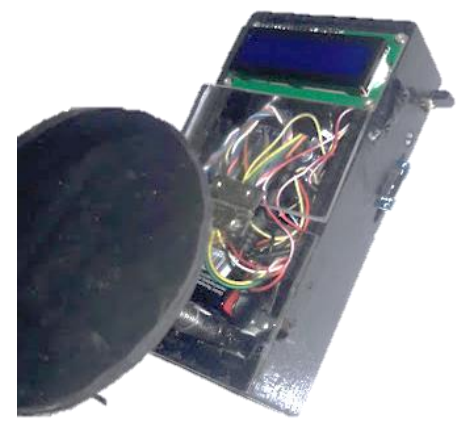

FIGURA 6. Protótipo final com disco de apoio acoplado (Autoria própria).

Após a construção do protótipo para a medição de força muscular, foi efetuado uma calibração para o ajuste inicial do fator de calibração presente no código do instrumento. O fator de calibração consiste na utilização de um número correspondente a proporcionalidade entre a diferença de potencial medida no Arduino, enviada pelas células de carga e amplificada pelo HX711 e o peso que está sob a célula. Com este fator de calibração é possível obter o valor inicial para certo peso padrão, para que então seja utilizado como base para as demais medidas. Com isso, faz-se necessária a utilização de um peso padrão, que tenha um valor conhecido e que possua uma incerteza de medição baixa, para então servir para a calibração do sistema. Foi usado um peso padrão de 850 gramas. O peso então foi medido utilizando uma balança analítica de precisão, com uma 
resolução de 0,1g. Onde, após 15 medições, obteve-se o peso de 851,4g com incerteza de aproximadamente $\pm 0,1 \mathrm{~g}$.

Após a medição do peso padrão, foi possível a utilização do mesmo para a calibração do protótipo. Foram feitas várias medições, posicionando o peso ao longo de todo o disco de apoio. O fator de calibração obtido pelo peso, foi implementado no código, concluindo então a construção do protótipo. A resolução foi ajustada para $0,01 \mathrm{~kg}$, ou seja, aproximadamente $10 \mathrm{~g}$ de incremento digital.

Após o ajuste do fator de calibração como valor inicial para o protótipo utilizando o peso padrão, o instrumento foi calibrado novamente com vários pesos padrões de laboratório de metrologia. O protótipo foi calibrado utilizando o método de calibração direta por comparação, ou seja, vários pesos de diferentes massas foram colocados no protótipo, onde o valor exibido no display foi comparado com o valor verdadeiro convencional dos pesos padrões. Assim, o protótipo foi calibrado com pesos de até $20 \mathrm{~kg}$, contendo uma incerteza máxima de $1 \mathrm{~g}$. O resultado é mostrado na Tabela 3.

TABELA 2. Valores da calibração efetuada no protótipo (Autoria própria).

\begin{tabular}{|c|c|c|c|c|}
\hline $\begin{array}{c}\text { Valor } \\
\text { verdadeiro }\end{array}$ & & Protó & & \\
\hline$(\mathrm{kg})$ & $\begin{array}{c}\text { Média das } \\
\text { Leituras (kg) }\end{array}$ & Erro (kg) & $\begin{array}{c}\text { Correção } \\
(\mathrm{kg})\end{array}$ & $\begin{array}{c}\text { Erro em \% } \\
\text { do VFE }\end{array}$ \\
\hline 0,00 & 0,00 & 0,000 & 0,000 & 0,000 \\
\hline 0,10 & 0,12 & $-0,023$ & 0,023 & $-0,047$ \\
\hline 0,50 & 0,53 & $-0,031$ & 0,031 & $-0,062$ \\
\hline 1,00 & 1,06 & $-0,055$ & 0,055 & $-0,110$ \\
\hline 2,00 & 2,08 & $-0,082$ & 0,082 & $-0,164$ \\
\hline 5,00 & 5,11 & $-0,112$ & 0,112 & $-0,224$ \\
\hline 7,50 & 7,62 & $-0,117$ & 0,117 & $-0,233$ \\
\hline 10,00 & 10,14 & $-0,142$ & 0,142 & $-0,284$ \\
\hline 12,50 & 12,65 & $-0,154$ & 0,154 & $-0,308$ \\
\hline 15,00 & 15,23 & $-0,231$ & 0,231 & $-0,462$ \\
\hline 17,50 & 17,75 & $-0,253$ & 0,253 & $-0,506$ \\
\hline 20,00 & 20,32 & $-0,321$ & 0,321 & $-0,642$ \\
\hline 30,00 & 30,44 & $-0,440$ & 0,440 & $-0,880$ \\
\hline 40,00 & 40,49 & $-0,494$ & 0,494 & $-0,988$ \\
\hline 50,00 & 50,53 & $-0,530$ & 0,530 & $-1,060$ \\
\hline
\end{tabular}

*Nota: VFE significa valor final da escala, que para a calibração corresponde a $50 \mathrm{~kg}$.

Os erros são calculados através das Equações 3 e 4, onde o erro máximo encontrado foi cerca de 530g, quando submetido a uma massa de $50 \mathrm{~kg}$, com uma incerteza de aproximadamente $\pm 20 \mathrm{~g}$. A incerteza dos resultados é baseada em uma incerteza combinada para um nível de confiança de aproximadamente $95 \%$. O Valor verdadeiro convencional (VVC), corresponde ao valor conhecido para os pesos padrões, dotados de incerteza também conhecida. A média corresponde a soma dos valores medidos no instrumento utilizando o peso padrão, dividido pelo número de vezes em que foi medido, quinze [15]. 


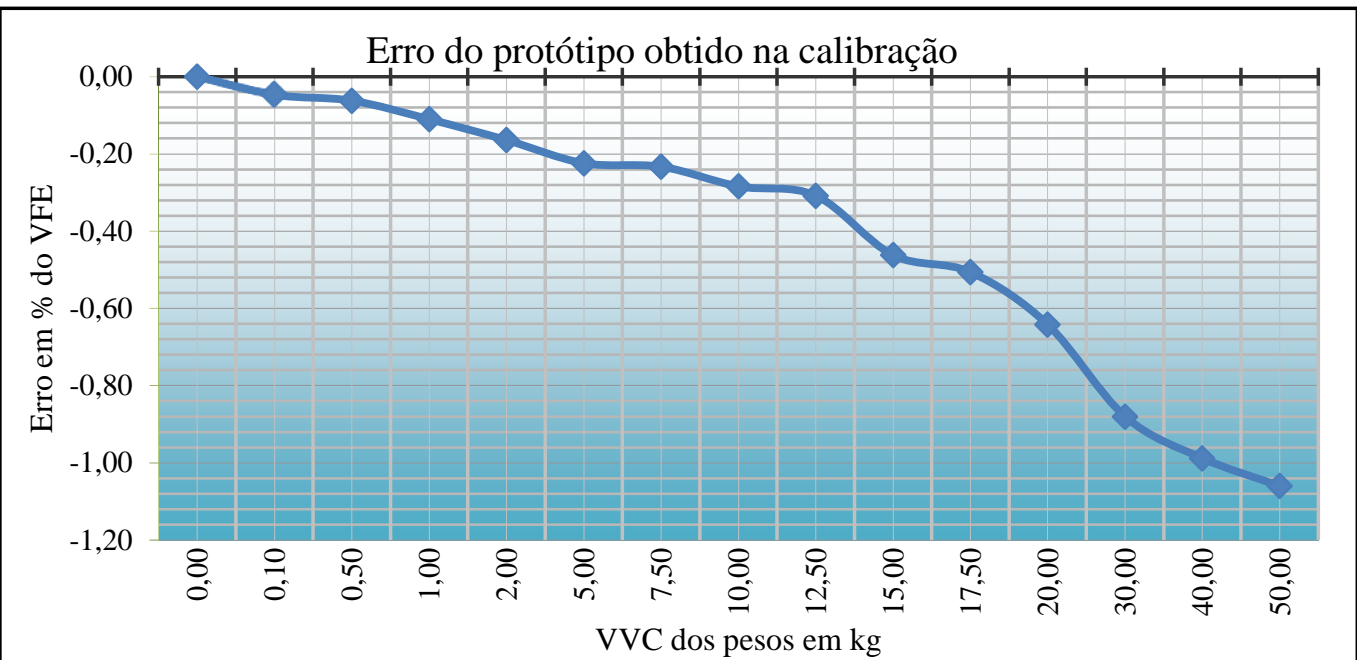

Figura 8: Gráfico do erro do protótipo em relação ao VFE em todos os pontos calibrados (Autoria própria).

Os resultados obtidos foram satisfatórios, mostrando que o instrumento é capaz de efetuar medições precisas ao ser submetido por forças de aproximadamente $500 \mathrm{~N}$. Por motivos didáticos e por motivo de não haver pesos suficientes para maiores massas, não houve testes acima dessa capacidade de 50kg. Porém, o resultado obtido já é o suficiente para mostrar que o instrumento pode ser utilizado em diagnósticos mais simples com pacientes reais.

\section{CONCLUSÃO}

De acordo com o apresentado, pode-se concluir que o protótipo para medição de força muscular de baixo custo possui um alto custo benefício, visto que ele apresenta medições precisas, com um erro máximo de aproximadamente $1 \%$ para o valor final de escala de $50 \mathrm{~kg}$ e teve um custo de fabricação de aproximadamente cinquenta reais. Logo, o protótipo deve então ser melhorado para a fabricação de um instrumento capaz de ser utilizado em pacientes, em consultas com profissionais especializados, e que seja melhorado com o tempo e experiência no mercado. Algumas melhorias podem ser feitas no instrumento como, por exemplo, a utilização de um display LCD maior, para a exibição de mais informações ao usuário, assim como a fabricação de uma placa de circuito própria para o instrumento, para assim, reduzir o tamanho do mesmo e melhorá-lo visualmente. Assim como a fabricação de uma melhor carcaça exterior. O instrumento também deve ser submetido a estudo de diferentes tipos de células de carga, pois existem vários tipos de célula de carga no mercado que podem facilmente se adequar ao protótipo. A forma de armazenar os dados também pode ser melhorada, transmitindo os dados diretamente para um servidor, via internet ou para o celular do usuário, utilizando um módulo bluetooth. Porém, o instrumento nessas condições iniciais de projeto, já atendeu os requisitos de ser um instrumento capaz de realizar medições com relativa precisão.

Assim, foi possível criar um instrumento preciso e de boa qualidade, utilizando ferramentas de materiais de baixo custo que possa ser utilizado como substituto para instrumentos de diagnósticos de força mais caros. Utilizando componentes baratos e o Arduino foi possível criar um instrumento que atendesse às expectativas de utilização em um teste de força, para qualquer membro do corpo. O protótipo possui grande capacidade de 
armazenamento e uma boa coleta de dados e apresenta um erro pequeno, que pode concorrer com outros instrumentos que já estão consolidados no mercado. Vale salientar que o protótipo foi criado e testado de forma empírica. A utilização do instrumento, ou semelhante deve ser feita por um profissional especializado. Um projeto futuro deste protótipo é a integração com o curso de medicina da universidade, visando um aprimoramento do instrumento com os problemas práticos e uma produção em escala considerável para uma futura patente.

\section{REFERÊNCIAS}

[1] RAMUZA. Origem história e curiosidades sobre a balança. Disponível em: $<$ https://www.ramuza.com.br/blog/origem-historia-e-curiosidades-sobre-a-balanca/>. Acesso em 28 maio 2019.

[2] YOUNG, HUGH D.; FREEDMAN, ROGER A. Física I. São Paulo: Pearson Education do Brasil, 2008.

[3] MARQUES MAC. A força. Alguns conceitos importantes. Lecturas EF y deportes, 8(46), 2002. Disponível em: < http://www.efdeportes.com/efd46/forca.htm>. Acesso em: 1 jun. 2019.

[4] KISNER C, COLBY LA. Exercícios Terapêuticos - Fundamentos e Técnicas. Barueri, SP: Manole, 2004. $841 \mathrm{p}$.

[5] INSTRUTHERM. Dinamômetro Academias (2019). Disponível em: <https://www.instrutherm.net.br/blog/dinamometroacademias/>. Acesso em 1 jun. 2019.

[6] ACTA FISIÁTRICA. Teste de força de preensão utilizando o dinamômetro Jamar (2006). Disponível em: <http://www.actafisiatrica.org.br/detalhe_artigo.asp?id=196>. Acesso em: 2 jun. 2019.

[7] SHOPFISIO. Dinamômetro de mão hidráulico Jamar. Disponível em: <https://www.shopfisio.com.br/dinamometro-de-mao-hidraulico-jamar-p1058625>. Acesso em 2 jun. 2019.

[8] MCROBERTS, Michael. Arduino Básico. São Paulo: Novatec Editora Ltda. 2011.

[9] ARDUINO UNO®. “Arduino UNO REV3.” Disponível em: <https://store.arduino.cc/usa/arduino-unorev3> Acesso em: 12 jul. 2019.

[10] EMBARCADOS. Arduino UNO. Disponível em: <https://www.embarcados.com.br/arduino-uno/>. Acesso em 4 jun. 2019.

[11] CARER, M.; CARRARO, E. (2010) Célula de carga. Disponível em: <http://hermes.ucs.br/ccet/demc/vjbrusam/inst/cel61.pdf >. Acesso em 1 jun. 2019.

[12] HALLIDAY, DAVID, RESNICK, ROBERTKRANE, KENNETH S. Física. Vol. 3 (5a. ed.). [s.1.]: Grupo Gen - LTC, 2000.

[13] ELETROGATE. Balança digital com Arduino. Aprenda a usar a célula de carga. Disponível em: <http://blog.eletrogate.com/balanca-digital-com-arduino-aprenda-a-usar-a-celula-de-carga/>. Acesso em 10 jun. 2019.

[14] LAFAYETTE INSTRUMENT EVALUATION. Lafayette Hand-Held Dynamometer. Disponível em: <http://lafayetteevaluation.com/products/lafayette-hand-held-dynamometer>. Acesso em 19 jul. 2019.

[15] ALBERTAZZI, ARMANDO G. Jr.; SOUSA, ANDRÉ R. Fundamentos de metrologia científica e industrial. São Paulo: Manole, 2008. 